\title{
Finite Element Analysis of Strap Lap Bonding Joints for Wood Powder/Polyethylene Composites with Combined Surface Treatment
}

\author{
Dongyan Zhou, a,b and Mingwei Di ${ }^{\text {a,* }}$
}

\begin{abstract}
A design for strap lap bond joints of wood powder/polyethylene composites (WP/PE) was proposed. The effects of combined treatment on surface properties of WP/PE and failure modes of WP/PE bonded by epoxy and acrylic ester were investigated. A finite element model of strap lap bond joints of WP/PE was established based on the elastoplasticity finite element method, and the effects of lap length and adhesive (epoxy and acrylic ester) on stress distributions and comprehensive displacements of strap lap bond joints of WP/PE were investigated. The results demonstrated that the bonding interface roughness of WP/PE was enhanced by the combined surface treatment. Active oxygen-containing functional groups were introduced to the sample surface. The finite element simulation results revealed that the Mises equivalent stress peaks and comprehensive displacements of strap lap bond joints were concentrated in lap zone ends and board connections, the stress distribution was independent of the lap length, and the Mises equivalent stress peaks and comprehensive displacements were independent of the adhesive.
\end{abstract}

Keywords: Wood powder/polyethylene composites; Surface treatment; Strap lap bonding joints; Numerical finite element simulation

Contact information: a: Key Laboratory of Bio-Based Material Science and Technology (Northeast Forestry University), Ministry of Education, Harbin, China; b: China Jiliang University, Hangzhou, China; *Corresponding author: dimingwei@126.com

\section{INTRODUCTION}

The wood powder/polyethylene composite (WP/PE) is a novel composite material that combines advantages of both wood and plastics. WP/PEs have been applied in various fields, including indoor/outdoor windows/doors, newsstands, containers, and interior panels of vehicles. In most situations, the structural connections of WP/PE have been achieved by bonding connections, mechanical connections, and welding connections. Bonding connections have attracted great attention due to their straight forward operation, miniaturized connectors, and seamless connections. However, the non-polar nature of polyethylene in WP/PE hinders their bonding (Hünnekens et al. 2018). Previous studies have demonstrated that seamless connections of WP/PE can only be achieved after surface treatment (Moghadamzadeh et al. 2011; Moritzer and Hopp 2017). Especially, the combined surface treatment of sanding then coating with a silane coupling agent followed by plasma discharge for WP/PE composites, was utilized to obtain a fast treatment method and a satisfactory bonding performance (Liu et al. 2010; Hou et al. 2017; Yáñezpacios and Martínmartínez 2017).

The bonding joints of WP/PE exist in various forms and the conventional bonding joints include single lap joints, double lap joints, strap lap joints, miter joints, and butt 
joints. Among various bonding joints, strap lap bonding joints have been widely applied because they do not suffer from loading bias in single lap joints nor demanding processing requirements or the high cost that is observed with double lap joints (Osnes and McGeorge 2009). However, strap lap bonding joints are limited by some drawbacks. For instance, a transitional adherent board is present between the adherends. The connections between the adherend and board tend to be weak sites for fracture failures of bonding joints. The failure of either connection surface will lead to bonding joint failures. Hence, the stability of strap lap bonding joints is typically poor. Although mechanical properties (e.g., strength) of strap lap bonding joints can be experimentally determined (Osnes and McGeorge 2005; Wang and Gunnion 2009; Sayman et al. 2013), their structural stress distribution cannot be tested or described. Currently, stress distributions in bonding joints can be numerically simulated by the finite element method, thus facilitating mechanical analysis for the design of complicated adhesive structures (Vaidya et al. 2008; Lu et al. 2013).

In this study, WP/PE samples after combined surface treatment were bonded by epoxy and acrylic ester. Finite element simulations of stress distributions in strap lap bonding joints were achieved by Abaqus/CAE finite element analysis software (Azari et al. 2012; Tang and Liu 2018), and the structures of the strap lap bonding joints were optimized by tuning their geometric parameters. Additionally, the effects of lap length and the elastic modulus of the adhesive on stress distributions and the comprehensive displacements of bonding joints were investigated (Razavi et al. 2018), thus providing references to the design of strap lap bonding joints.

\section{EXPERIMENTAL}

\section{Materials}

The WP/PE were synthesized by extrusion of a mixture of poplar powder (size = 380 to $830 \mu \mathrm{m}$, mass fraction $=60 \%$ ) (Deqing Country-Licensing, Lin Wood Flour Co. Ltd., Zhejiang Provice, China), high-density polyethylene (mass fraction $=35 \%$ ) (Daqing Petrochemical Co., Ltd., Heilongjiang Province, China), coupling agent (maleic anhydride grafted polyethylene, mass fraction $=3 \%$ ) (Ningbo Nengzhiguang New Material Technology Co., Ltd., Zhejiang Province, China), and lubricant (mass fraction $=2 \%$ ) (Hangzhou Jinwei Nanometer New Materials Co., Ltd., Zhejiang Provice, China). After the sample was extruded and molded with an extruder (Double Screw Extrusion Machine; Nanjing Rubber Factory, Nanjing, China), it was cut by a cutting machine to the size of 40 $\mathrm{mm} \times 25 \mathrm{~mm} \times 4 \mathrm{~mm}$, and the shape was rectangular. The $\gamma$-glycidyl oxypropyl triethoxy silane (KH-560 silane coupling agent) (Heilongjiang Institute of Petrochemistry, Harbin, China) was dissolved in absolute ethanol to obtain a silane coupling agent solution with a mass fraction of 5\%. The WP/PE samples were bonded by epoxy resin adhesive (Heilongjiang Institute of Petrochemistry, Harbin, China) and two-component acrylic ester adhesives (Heilongjiang Institute of Petrochemistry, Harbin, China), respectively, and the thickness of the adhesive layer was 0.1 to $0.15 \mathrm{~mm}$. Epoxy resin adhesive was solidified at room temperature for $24 \mathrm{~h}$ and then at $50{ }^{\circ} \mathrm{C}$ for $4 \mathrm{~h}$, while acrylic ester adhesive was solidified at room temperature for $24 \mathrm{~h}$. 


\section{Methods}

\section{Surface treatment}

The surface treatment was applied to samples via the following three steps. First, samples were polished using 180-mesh sandpaper. Second, the surface of WP/PE was coated with $5 \mathrm{wt} \% \mathrm{KH}-560$ ethanol solution, after which the treated samples were left at room temperature for $10 \mathrm{~min}$. Finally, the samples were underwent a plasma surface treatment by a jet low-temperature plasma processor (GSL-1100X-PJF-A; Shenyang Kejing Automation Equipment Co. Ltd., Shenyang, China). Under ambient air at room temperature and atmospheric pressure the specimens experienced a discharge gap of 30 $\mathrm{mm}$ and treated for $30 \mathrm{~s}$.

\section{Tests and analyses}

Fourier transform infrared (FTIR) spectral analysis with an attenuated total reflectance (ATR) mode was conducted (Magna-IR560; Nicolet Co. Ltd., USA). The resolution was $4 \mathrm{~cm}^{-1}$, the scanning range was 4000 to $400 \mathrm{~cm}^{-1}$, and the quantity of scanning cycles was 40 . The treated WP/PE were characterized by a universal mechanical testing machine (SANS-CMT5504; Shenzhen Suns Co. Ltd., Shenzhen, China) for tensile strength and tensile failure tests of bonding joints with a loading speed of $5 \mathrm{~mm} / \mathrm{min}$, according to ASTM D905-08 (2013). The finite element simulations of bonding joints were achieved using Abaqus 6.13 software (Dassault Systemes Simulia Corporation, The State of Rhode Island and Providence Plantations, USA). The length of bond joint lap zone is 5 $\mathrm{mm}, 10 \mathrm{~mm}, 15 \mathrm{~mm}$, and $18 \mathrm{~mm}$, and the bond joint lap zone is symmetrical on both sides. Figure 1 shows the geometric sizes of $15 \mathrm{~mm}$ bond joints and loading constraint of the adhesive joints.

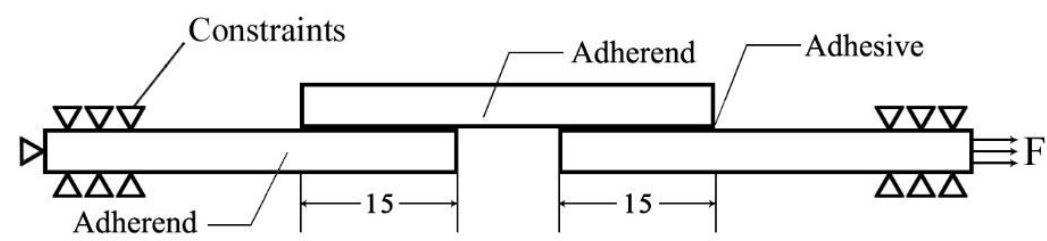

Fig. 1. Schematic diagram of the geometric size of $15 \mathrm{~mm}$ and loading constraint of the adhesive joints

\section{RESULTS AND DISCUSSIONS}

\section{FTIR Analysis}

Figure 2 shows the FTIR spectra of WP/PE before and after the combined treatments. As observed, the WP/PE before surface treatment (Curve 1) were characterized by five absorption bands, which corresponded to the symmetric stretching vibration peaks of $-\mathrm{CH}_{2}$ in alkanes $\left(2918 \mathrm{~cm}^{-1}\right)$, antisymmetric stretching vibration absorption peak in alkanes $\left(2848 \mathrm{~cm}^{-1}\right)$, in-plane bending vibration absorption peak of alkane, and out-ofplane bending vibration absorption peak of C-H of alkenes $\left(1471 \mathrm{~cm}^{-1}, 717 \mathrm{~cm}^{-1}\right)$. The stretching vibration absorption peak of $\mathrm{C}-\mathrm{O}$ at $1029 \mathrm{~cm}^{-1}$ can be attributed to surface oxidization of WP/PE during processing and storage, further demonstrating that the composite surface was primarily polyethylene. The WP/PE after the combined treatment (Curve 2) was characterized by the characteristic absorption peak of Si-O-C (1103 $\left.\mathrm{cm}^{-1}\right)$ and stretching vibration absorption peaks of $-\mathrm{OH}$ and $\left(3348 \mathrm{~cm}^{-1}\right) \mathrm{C}=\mathrm{O}\left(1722 \mathrm{~cm}^{-1}\right.$ and 1639 
$\left.\mathrm{cm}^{-1}\right)$. Additionally, the intensity of the stretching vibration absorption peak of C-O (1029 $\mathrm{cm}^{-1}$ and $1233 \mathrm{~cm}^{-1}$ ) statistically increased. Under plasma, the Si-O-C covalent bonds and the Si-O-Si silane film network structures were generated by polycondensation between the silane coupling agent coating and the - $\mathrm{OH}$ groups on the composite surface. The plasma introduced a considerable amount of polar oxygen-containing functional groups, such as $\mathrm{C}-\mathrm{O}$ and $\mathrm{C}=\mathrm{O}$ on the composite surface.

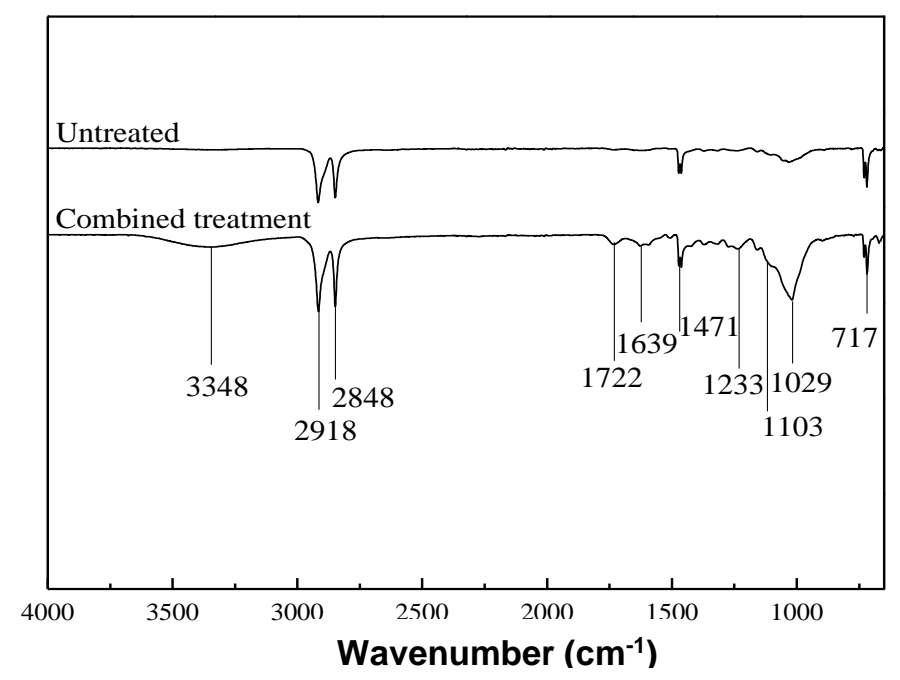

Fig. 2. FTIR spectra of the WP/PE surface before and after combined treatment

\section{Bonding Strength}

Figure 3 shows the tensile strength of the untreated and combined treated WP/PE adhesive joints bonded with the epoxy resin and acrylic ester adhesives. Figure 3 also shows that the untreated WP/PE bonding joints had an extremely low tensile strength because of the non-polar PE composition on the material surface. Additionally, the adhesive strength of the joints bonded with the epoxy resin and acrylic ester adhesives was improved after the combined treatment. It was observed that the silane coupling agent combined with the discharge treatment changed the surface properties of the WP/PE and improved the bonding force between the material surface and adhesive bonding strength.

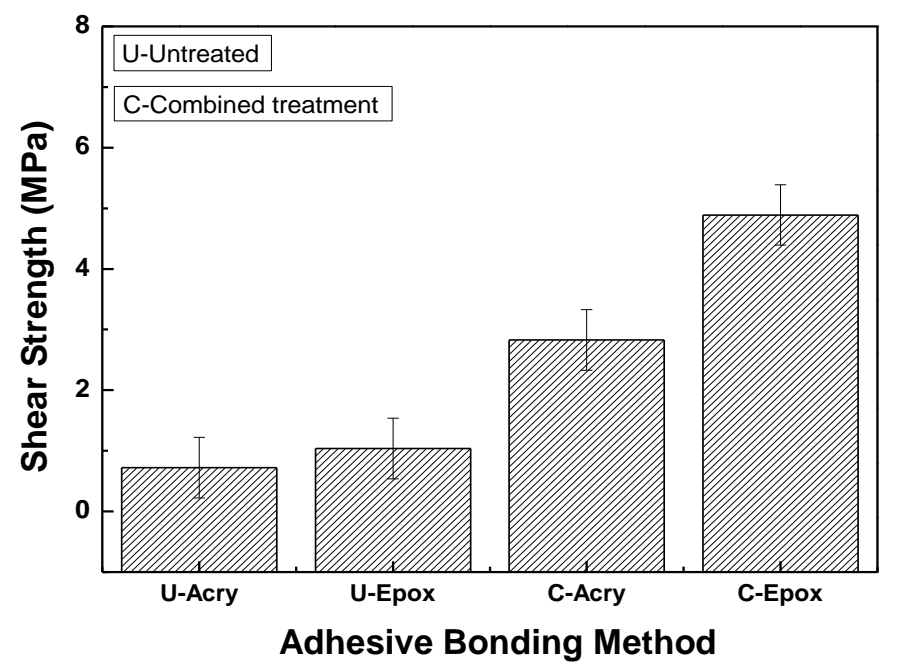

Fig. 3. Shear strength of the untreated and combined treatment WP/PE adhesive joints 


\section{Failure Modes of the Adhesive Joints}

Figure 4 shows the failure sections of strap lap bonding joints with combined treatment at the tensile shear stress state. The bonding can be evaluated based on the failure section of the bonding joint. As observed, the failure modes of bonding joints with combined treatment involved damage within the material itself, regardless of lap length. This was attributed to the low tensile strength of the adherend and high bond strength of the interface. The tensile strength of WP/PE was lower than the bond strength of the interfaces with the combined treatment, and the fracture failures of bonding joints were observed at stress concentration sites. In summary, the board connections of strap lap bonding joints were exposed to adherend damages under external forces.
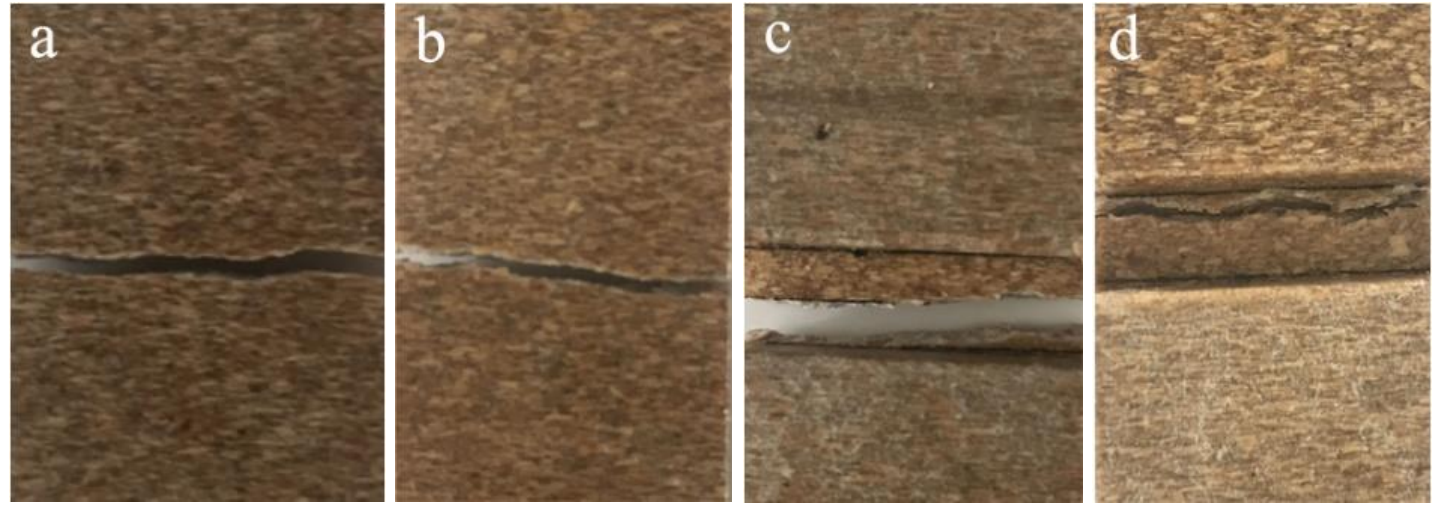

Fig. 4. Failure section of the strap lap bonding joint with different lap lengths: (a) Epoxy resin, lap length of $15 \mathrm{~mm}$; (b) Acrylic ester, lap length of $15 \mathrm{~mm}$; (c) Epoxy resin, lap length of $18 \mathrm{~mm}$; and (d) Acrylic ester, lap length of $18 \mathrm{~mm}$

\section{Construction of the Finite Element Model}

In this study, a finite element simulation model was established by the elastoplasticity finite element method using Abaqus 6.13. The element was a hexahedral solid element, and the finite element mesh was a three-dimensional eight-node brick element. The overlapping area and adhesive layer were divided by a quadrilateral mesh with a $0.05 \mathrm{~mm}$ mesh size. Table 1 lists the material parameters in Abaqus/CAE, and the load $(F)$ was $0.5 \mathrm{kN}$. According to the models proposed by Sayman et al. (2013) and Vaidya et al. (2008), the adhesive layer and adherend are regarded as isotropic elastoplastic materials. In finite element analysis, it is assumed that connections of structural components are perfect, the bonding surface is defect-free, no spew fillets are present on joint ends, displacements of coupling nodes are consistent, and the bonding interface is perfectly bonded. Because model deformation along its thickness direction is negligible, solid elements were employed for the model. One end of the model is fixed and the other end is exposed to axial tensile load. To achieve simulation of the adhesive layer, a solid adhesive layer is added between the joint boards. In finite element simulation by Abaqus/CAE, it was assumed that the adhesive was exposed to slight deformation and the nonlinearity of materials was considered (Zhou and Di 2019) to approximate the mechanical properties of bonding joints. Table 1 shows the Young's modulus (tensile modulus) and shear modulus of the material that were tested by a universal mechanical testing machine in accordance with ASTM D638-14 (2014). The Poisson ratio of materials was calculated according to Eq. 1 (Huang et al. 2012), 


$$
G=\frac{E}{2(1+v)}
$$

where $G$ is the Shear modulus (GPa), $E$ is the Young's modulus (GPa), and $v$ is the Poisson ratio.

Table 1. Main Properties of the Materials and Adhesives Used

\begin{tabular}{|c|c|c|c|}
\hline Material & $\begin{array}{c}\text { Young's Modulus }(E) \\
(\mathrm{GPa})\end{array}$ & Poisson Ratio $(v)$ & $\begin{array}{c}\text { Density } \\
\left(\mathrm{g} / \mathrm{cm}^{3}\right)\end{array}$ \\
\hline WP/PE Composite & 2.200 & 0.30 & 1.1 \\
\hline Epoxy Resin Adhesive & 1.900 & 0.38 & 1.02 \\
\hline Acrylic Ester Adhesive & 0.230 & 0.35 & 0.965 \\
\hline
\end{tabular}

\section{Analysis of the Mises Equivalent Stress}

Figure 5 shows the Mises equivalent stresses of strap lap bonding joints of WP/PE bonded by epoxy resin adhesive and acrylic ester adhesive, respectively. The lap lengths of bonding joints were $5 \mathrm{~mm}$. The Mises equivalent stress reflects the stress concentrations and the weak zone of the adhesive structure was determined based on Mises equivalent stress. The Mises equivalent stress can be expressed by Eq. 2,

$$
\sigma_{e}=\sqrt{\frac{1}{2}}\left[\left(\sigma_{1}-\sigma_{2}\right)^{2}+\left(\sigma_{2}-\sigma_{3}\right)^{2}+\left(\sigma_{1}-\sigma_{3}\right)^{2}\right]^{\frac{1}{2}}
$$

where $\sigma_{\mathrm{e}}$ is the Mises equivalent stress, $\sigma_{1}$ is the first principal stress, $\sigma_{2}$ is the second principal stress, and $\sigma_{3}$ is the third principal stress.

As observed, Mises equivalent stress peaks of strap lap bonding joints with lap lengths of $5 \mathrm{~mm}$ were located at lap zone ends and in board connection area. The severe stress concentrations at lap zone ends and adherend board connections demonstrated that all loads were applied on lap zone ends and board connections. As a result, lap zone ends and adherend board connections were weak adhesive zones. Hence, it can be deduced that fracture failure sites of laminate bonding joints were located at lap zone ends and board connections. The finite element simulation results were consistent with experimental results, where the bonding joint fractures were present at lap zone ends and board connections.
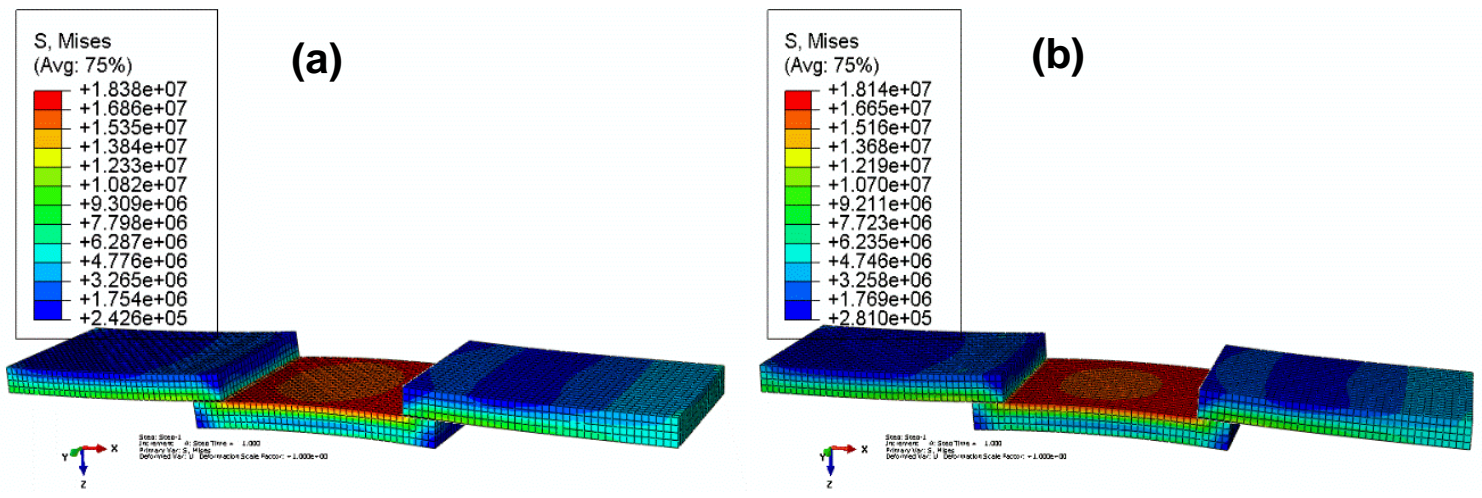

Fig. 5. Mises equivalent stress distribution diagram of the strap lap joint with different adhesive: (a) epoxy resin, lap length of $5 \mathrm{~mm}$ and (b) acrylic ester, lap length of $5 \mathrm{~mm}$ 
Figure 6 depicts Mises equivalent stresses of strap lap bonding joints of WP/PE with different lap lengths and bonded by epoxy resin adhesive and acrylic ester adhesive, respectively. Overall, the intensities of Mises equivalent stress peaks at lap zone ends and strap lap bonding joints slightly increased with the lap length and severe stress concentrations were present at lap zone ends and laminate bonding joints. At constant lap length, Mises equivalent stress peaks of strap lap bonding joints of WP/PE by epoxy resin and acrylic ester were consistent, demonstrating that concentrations of Mises equivalent stress at strap lap bonding joints were not effectively relieved by increasing lap length. The elastic modulus of the adhesive had a negligible effect on Mises equivalent stress of strap lap bonding joints.
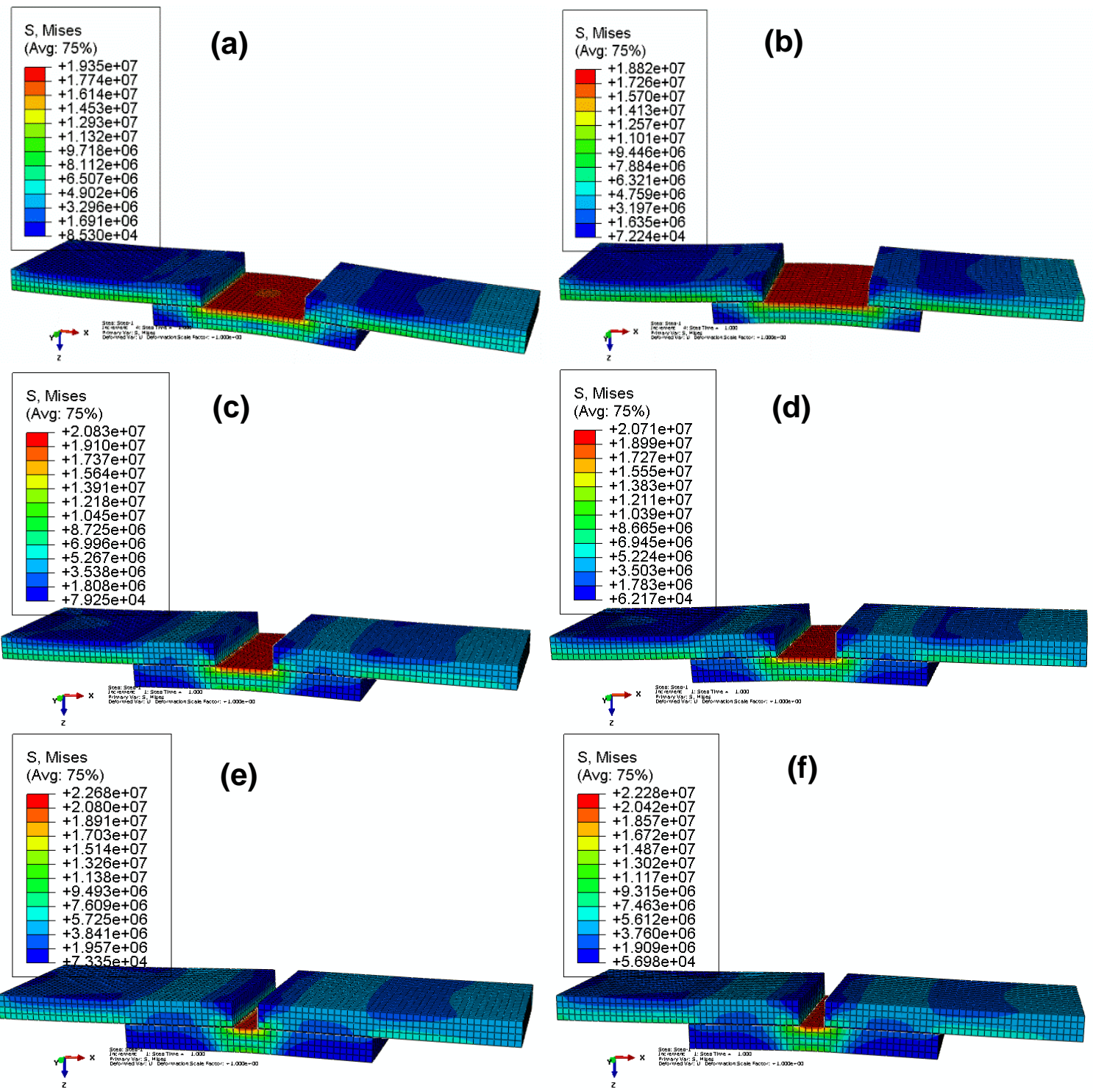

Fig. 6. Mises equivalent stress distribution diagrams of the strap lap bonding joint with different lap length: (a) Epoxy resin, lap length of $10 \mathrm{~mm}$; (b) gth of $10 \mathrm{~mm}$; (c) Epoxy resin, lap length of $15 \mathrm{~mm}$; (d) Acrylic ester, lap length of $15 \mathrm{~mm}$; (e) Epoxy resin, lap length of $18 \mathrm{~mm}$; and ( $\mathrm{f}$ ) Acrylic ester, lap length of $18 \mathrm{~mm}$ 


\section{Comprehensive Displacement Analysis}

In finite element analysis by Abaqus/CAE, the comprehensive displacement was also regarded as the equivalent relative displacement, which was an integration of relative displacements of bonding joints in $\mathrm{X}, \mathrm{Y}$, and $\mathrm{Z}$ directions. The displacement had an absolute value, and it denoted displacement or deformation of the lap zone in the adhesive structure.

Figure 7 illustrates comprehensive displacements of strap lap bonding joints of WP/PE bonded by epoxy resin adhesive and acrylic ester adhesive, respectively. The lap length of bonding joints was $5 \mathrm{~mm}$. As observed, the comprehensive displacements of bonding joints of WP/PE bonded by epoxy resin and acrylic ester followed similar trends, and the maximum displacements of both bonding joints were present at the strap lap bonding joint of the adherend. The comprehensive displacements of bonding joints of WP/PE bonded by acrylic ester and epoxy resin were highly consistent, further demonstrating that the strap lap bonding joint was the maximum deformation zone in bonding joints and the effect of the elastic modulus of the adhesive on comprehensive displacement was negligible. This was consistent with experimental results, where the fractures of bonding joints were initiated at strap lap bonding joints.
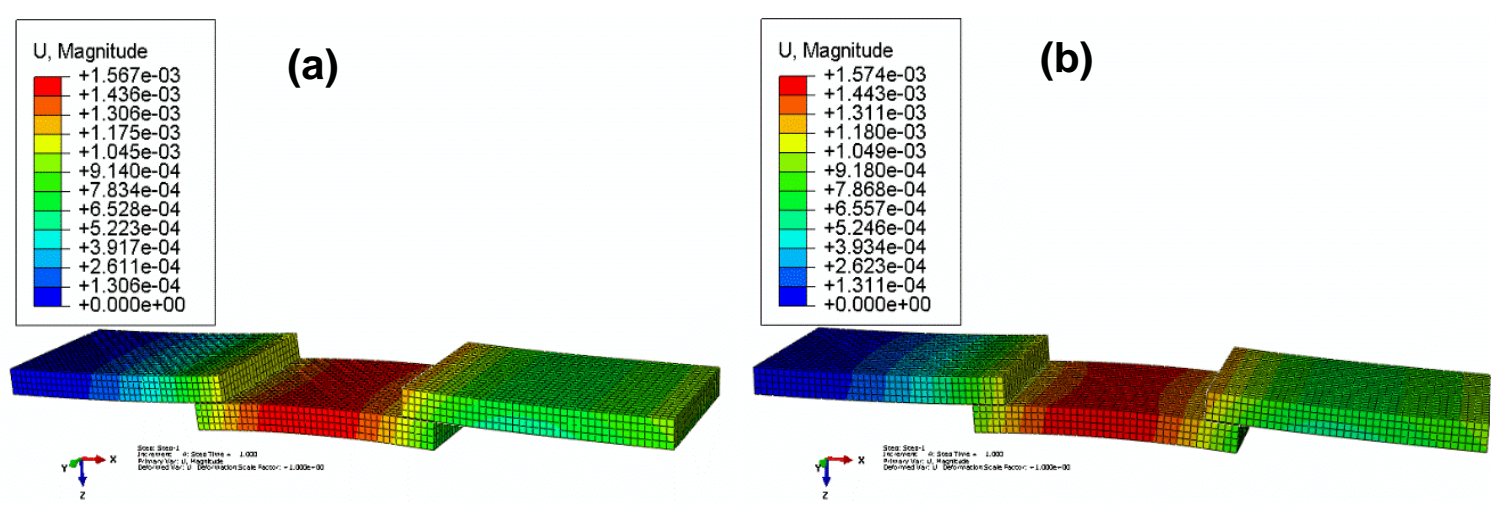

Fig. 7. Comprehensive displacement diagram of the strap lap bonding joint with different adhesives:(a) epoxy resin, lap length of $5 \mathrm{~mm}$, and (b) acrylic ester, lap length of $5 \mathrm{~mm}$

Figure 8 shows the comprehensive displacements of strap lap bonding joints of WP/PE with different lap lengths. With small lap lengths (5 and $10 \mathrm{~mm})$, the comprehensive displacement of adherend strap lap bonding joints increased and then decreased along the lap zone; the average comprehensive displacement was relatively large. With large lap lengths (15 and $18 \mathrm{~mm}$ ), the comprehensive displacement of adherend strap lap was transferred toward the lap zone edge and decreased as the lap lengt.2h increased. With constant lap length, comprehensive displacements of bonding joints of WP/PE bonded by epoxy resin and acrylic ester were consistent. As the lap length increased, the comprehensive displacement of the bonding joint was transferred from strap lap bonding joint to lap zone ends and the lap zone of bonding joints bore partial displacement at the adherend board, resulting in reduced total displacement of the strap lap bonding joint. This served as an indicator that the total displacement of the strap lap bonding joint was primarily determined by lap length. As the lap length increased, the area of loading zone of the lap zone increased, the capability of bonding joints bearing structural deformation was enhanced, and the total displacement decreased. The elastic modulus of the adhesive had a negligible effect on the total displacement of the bonding joint. It should 
be noted that increased lap length led to increased internal defects of the adhesive layer, thus reducing the bonding strengths of the bonding joints.
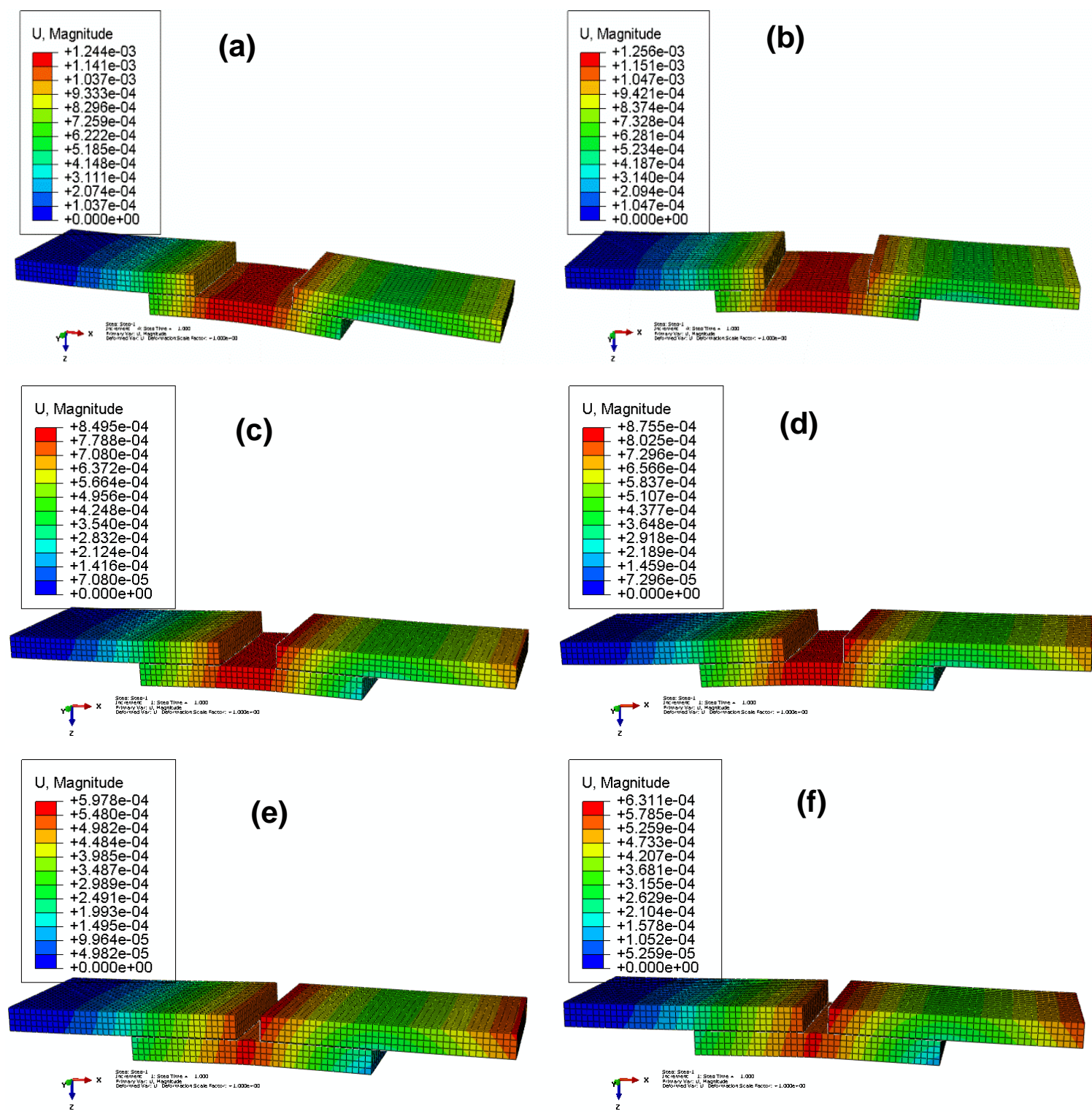

Fig. 8. Comprehensive displacement diagram of the strap lap bonding joint with different lap lengths:(a) Epoxy resin, lap length of $10 \mathrm{~mm}$; (b) Acrylic ester, lap length of $10 \mathrm{~mm}$; (c) Epoxy resin, lap length of $15 \mathrm{~mm}$; (d) Acrylic ester, lap length of $15 \mathrm{~mm}$; (e) Epoxy resin, lap length of 18 $\mathrm{mm}$; and (f) Acrylic ester, lap length of $18 \mathrm{~mm}$

In summary, strap lap bonding joints are weak zones of bonding joints and readily exposed to fracture failure of bonding joints (Nguyen et al. 2013), according to the distribution of Mises equivalent stresses of strap lap bonding joints. The comprehensive displacement of strap lap bonding joints at strap lap bond connections was relatively large, demonstrating that strap lap bond connections were areas with maximum variations of displacement in bonding joints. The experimental results were consistent with finite element simulation results. 
According to finite element simulation results, fracture failures of strap lap bonding joints tended to be in the board tearing pattern. Because the Mises equivalent stress increased slightly with the lap length, the bearing capacity of bonding joints was independent from the lap length. Hence, the lap length of the strap lap bonding joint in the non-bearing area with moderate material strength shall be minimized (Kim et al. 2008; Tsouvalis and Karatzas 2011; Gültekin et al. 2014). The comprehensive displacement decreased as the lap length increased, demonstrating that the deformation resistance of the bonding joint was proportional to its lap length. The lap length of the non-bearing lap zone with large deformations yet moderate requirements of bonding strength should be maximized.

According to the failure section of strap lap bonding joints and the finite element simulation results, the strengths of strap lap bonding joints of WP/PE are closely related to adherend properties, surface treatment methods (Da Silva et al. 2009), lap length, and adhesive properties (Da Silva et al. 2008). Due to the high requirements of tensile strength of the adherend by strap lap bonding joints, the surface treatment method should be selected according to the properties of the materials and adhesives. For the design of strap lap bonding joints, the resistance of strap lap bonding joints to fracture failure and structural deformation, as well as the bearing capacity of bonding joint connectors, is proportional to the tensile strength of the adherend (You et al. 2007) .

The finite element analysis in this study was based on certain assumptions. First, it was assumed that the bonding interface was perfectly bonded. Second, the anisotropic WP/PE were assumed to be isotropic. Third, viscoelastic adhesives were assumed to be elastic materials. Despite the possible deviations of finite element simulation results were caused by these assumptions, finite element simulations of joint stress provided valuable references for the design of adhesive structures of WP/PE as stress distribution and the comprehensive displacement of strap lap bonding joints cannot be obtained experimentally.

\section{CONCLUSIONS}

1. The effective connections of wood powder/polyethylene (WP/PE) joints were achieved by the development of chemical bond connections of WP/PE after the combined surface treatment and adhesives. The failure modes of strap lap bonding joints were fracture failures of the lap zone and the failure zone of the bonding joints was located at the board connection of the lap zone, regardless of the lap length.

2. Mises equivalent stress and comprehensive displacement of strap lap bonding joints were concentrated at bonding joint ends and laminate bonding joints. The strap lap bond connections were fracture failure sites of bonding joints. This was consistent with the results of bond strength testing.

3. The elastic moduli of adhesives had negligible effects on stress distributions in strap lap bonding joints of WP/PE, and the lap length of strap lap bonding joints had negligible effects on Mises equivalent stress. Specifically, the peak intensity of Mises equivalent stress increased slightly, and comprehensive displacement decreased as the lap length increased. 
4. For strap lap bonding joints of WP/PE, high bonding strength and low cohesive strength of WP/PE after surface treatment led to fracture failures of bonding joints, resulting in poor performance. Hence, the surface treatment method should be selected based on the joint and material properties, and the lap zone thickness of the strap lap bonding joints of WP/PE should be increased, or the reinforcing designs should be included. For construction engineering parts with moderate requirements on bonding strength, acrylic ester was preferred as it can achieve rapid bonding of the adhesive structure compared to epoxies.

\section{ACKNOWLEDGMENTS}

This study was supported by the National Natural Science Foundation of China (Grant No. 31670567) and the Fundamental Research Funds for the Central Universities of China (2572017EB06).

\section{REFERENCES CITED}

ASTM D638-14 (2014). "Standard test method for tensile properties of plastics," ASTM International, West Conshohocken, PA, USA.

ASTM D905-08 (2013). "Standard test method for strength properties of adhesive bonds in shear by compression loading," ASTM International, West Conshohocken, PA, USA.

Azari, S., Ameli, A., Datla, N. V., Papini, M., and Spelt, J. K. (2012). "Effect of substrate modulus on the fatigue behavior of adhesively bonded joints," Materials Sciences and Engineering: A 534, 594-602. DOI: 10.1016/j.msea.2011.12.014

Da Silva, L. F. M., Carbas, R. J. C., Critchlow, G. W., Figueiredo, M. A. V., and Brown, K. (2009). "Effect of material, geometry, surface treatment and environment on the shear strength of single lap joints," International Journal of Adhesion and Adhesives 29(6), 621-632. DOI: 10.1016/j.ijadhadh.2009.02.012

Da Silva, L. F. M., Critchlow, G. W., and Figueiredo, M. A. V. (2008). "Parametric study of adhesively bonded single lap joints by the Taguchi method," Journal of Adhesive Science and Technology 22(13), 1477-1494. DOI: 10.1163/156856108X309585

Gültekin, K., Akpinar, S., and Özel, A. (2014). "The effect of the adherend width on the strength of adhesively bonded single-lap joint: experimental and numerical analysis," Composites Part B: Engineering 60, 736-745. DOI:

10.1016/j.compositesb.2014.01.022

Hou, Y. S., Yan, S., Guo, X., and Di, M. W. (2017). "Combined surface treatment of polyethylene wood-plastic composites to achieve rapid bonding with desired adhesion properties," BioResources 12(3), 6434-6445. DOI: 10.15376/biores.12.3.6434-6445

Huang, R. Z., Xiong, W., Xu, X. W., and Wu, Q. L. (2012). "Thermal expansion behavior of co-extruded wood-plastic composites with glass-fiber reinforced shells," BioResources 7(4), 5514-5526. DOI: 10.15376/biores.7.4.5514-5526

Hünnekens, B., Avramidis, G., Ohms, G., Krause, A., Viöl, W., and Militz, H. (2018). "Impact of plasma treatment under atmospheric pressure on surface chemistry and surface morphology of extruded and injection-molded wood-polymer composites (WPC)," Applied Surface Science 441, 564-574. DOI: 10.1016/j.apsusc.2018.01.294 
Kim, T. H., Kweon, J. H., and Choi, J. H. (2008). "An experimental study on the effect of overlap length on the failure of composite-to-aluminum single-lap bonded joints," Journal of Reinforced Plastics and Composites 27(10), 1071-1081. DOI: 10.1177/0731684407087074

Liu, Y., Tao, Y., Lv, X., Zhang, Y., and Di, M. W. (2010). "Study on the surface properties of wood/polyethylene composites treated under plasma," Applied Surface Science 257(3), 1112-1118. DOI: 10.1016/j.apsusc.2010.08.032

Lu, W., Hu, Y. C., Yao, J., and Li, Y. F. (2013). "Optimization and simulation research of tensile properties of wood lap joint," BioResources 8(1), 1409-1419. DOI: 10.15376/biores.8.1.1409-1419

Moghadamzadeh, H., Rahimi, H., Asadollahzadeh, M., and Hemmati, A. R. (2011). "Surface treatment of wood polymer composites for adhesive bonding," International Journal of Adhesion and Adhesives 31(8), 816-821. DOI: 10.1016/j.ijadhadh.2011.08.001

Moritzer, E., and Hopp, M. (2017). "Bonding of wood-plastic composites (WPC)material and surface modification for special applications," Welding in the World 61(5), 1029-1038. DOI: 10.1007/s40194-017-0487-0

Nguyen, T. C., Bai, Y., Zhao, X. L., and Al-Mahaidi, R. (2013). "Curing effects on steel/CFRP double strap joints under combined mechanical load, temperature and humidity," Construction and Building Materials 40, 899-907. DOI:

10.1016/j.conbuildmat.2012.11.035

Osnes, H., and McGeorge, D. (2009). "Experimental and analytical strength analysis of double-lap joints for marine applications," Composites Part B: Engineering 40(1), 29-40. DOI: 10.1016/j.compositesb.2008.07.002

Osnes, H., and McGeorge, D. (2005). "Analysis of over laminated double-lap joints," Composites Part B: Engineering 36(6-7), 544-558. DOI: 10,1016/jcompositesb.2005.01.002

Razavi, S. M. J., Ayatollahi, M. R., Majidi, H. R., and Berto, F. (2018). “A strain-based criterion for failure load prediction of steel/CFRP double strap joints," Composite Structures 206, 116-123. DOI: 10.1016/j.compstruct.2018.08.046

Sayman, O., Ozen, M., and Korkmaz, B. (2013). "Elasto-plastic stress distributions in adhesively bonded double lap joints," Materials \& Design 45, 31-35.

DOI: 10.1016/j.matdes.2012.09.005

Tang, H. Q., and Liu, L. Q. (2018). "A novel metal-composite joint and its structural performance," Composite Structures 206, 33-41. DOI: 10.1016/j.compstruct.2018.07.111

Tsouvalis, N. G., and Karatzas, V. A. (2011). "An investigation of the tensile strength of a composite-to-metal adhesive joint," Applied Composite Materials 18(2), 149-163. DOI: $10.1007 / \mathrm{s} 10443-010-9137-\mathrm{z}$

Vaidya, U. K., Serrano, J. C., Villalobos, A., Sands, J., and Garner, J. (2008). “Design and analysis of a long fiber thermoplastic composite tail cone for a tank gun training round," Materials \& Design 29(2), 305-318. DOI: 10.1016/j.matdes.2007.02.010

Wang, C. H., and Gunnion, A. J. (2009). "Optimum shapes of scarf repairs," Composites Part A: Applied Science and Manufacturing 40(9), 1407-1418. DOI: 10.1016/j.compositesa.2009.02.009

You, M., Yan, Z. M., and Zheng, X. L. (2007). "A numerical and experimental study of gap length on adhesively bonded aluminum double-lap joint," International Journal of Adhesion and Adhesives 27(8), 696-702. DOI: 10.1016/j.ijadhadh.2007.02.005 
Yáñezpacios, A. J., and Martínmartínez, J. M. (2017). "Surface modification and improved adhesion of wood-plastic composites (WPCs) made with different polymers by treatment with atmospheric pressure rotating plasma jet," International Journal of Adhesion and Adhesives 77, 204-213. DOI: 10.1016/j.ijadhadh.2017.06.001

Zhou, D. Y., and Di, M. W. (2019). "Numerical simulation analyses of single lap joints for wood-PE composites formed with epoxy and acrylic ester adhesives," BioResources 14(3), 5908-5922. DOI: 10.15376/biores.14.3.5908-5922

Article submitted: December 16, 2019; Peer review completed: February 29, 2020; Revised version received: March 6, 2020; Accepted: March 15, 2020; Published: March 18, 2020. DOI: 10.15376/biores.15.2.3112-3124 